\title{
Concepción espacial y literatura emblemática en los dramas pastoriles de Lope de Vega
}

\author{
Space Conceptions and Emblematic Literature \\ in Lope de Vega's Pastoral Dramas
}

\author{
Francisco Sáez Raposo \\ Universidad Complutense de Madrid \\ f.saez@filol.ucm.es \\ ORCID iD: https://orcid.org/0000-0001-7584-1769
}

\section{RESUMEN}

El presente artículo establece vínculos entre la cultura conceptual e iconográfica que surgió a partir de la publicación del Emblematum Liber de Andrea Alciato en 1531 y los dramas pastoriles escritos por Lope de Vega entre 1590 y 1615 aproximadamente. El objetivo definitivo no es solo encontrar menciones a ciertos emblemas a nivel textual. La intención es, incluso, ir un poco más lejos, esto es, tratar de establecer, a partir de la representación de unos «modos de ver», conexiones entre determinadas concepciones escénicas y casos concretos incluidos en la literatura emblemática. En otras palabras, determinar la impronta visual con la que Lope concibió algunas de las escenas de sus dramas pastoriles.

Palabras Clave: Emblema; Alciato; drama pastoril; Lope de Vega; espacio dramático; puesta en escena; escenografía.

\begin{abstract}
This essay establishes links between the conceptual and iconographic culture that emerged from the publication of the Emblematum Liber by Andrea Alciato in 1531 and pastoral dramas written by Lope de Vega between 1590 and 1615 approximately. The ultimate aim is not only to find mentions of certain emblems at a textual level. The intention is to go even a little bit further, that is, to try to draw connections, from the representation of some "ways of seeing", between certain scenic conceptions and specific cases included in the emblematic literatura. In other words, to determine the visual imprint with which Lope de Vega conceived some of the scenes of his pastoral dramas.
\end{abstract}

Key words: Emblem; Alciato; Pastoral drama; Lope de Vega; Dramatic space; Staging; Scenography. 
En 1531, la publicación del Emblematum Liber de Andrea Alciato en Augsburgo inició un nuevo género en el que se combinaban un lema, una imagen y un poema con el fin de crear una unidad mayor de significado. Sustentada por la larga tradición de la cultura simbólica medieval, esta estructura tripartita planteaba un juego de ingenio en el que se interrelacionaban los tres elementos para subrayar un concepto específico. Los emblemas nacieron en ese momento, y muy pronto se convirtieron en una de las principales fuentes de referencias iconográficas y de información usada por artistas de todas las disciplinas para encontrar inspiración a la hora de componer sus obras. Los emblemas tuvieron un impacto crucial en la cultura del Renacimiento y el Barroco.

Un emblema es un producto gráfico, simbólico y retórico que aparece en la forma material de libro, pero su propia naturaleza conceptual le proporciona la habilidad de expandirse a otros ámbitos artísticos, siendo uno de ellos, obviamente, el teatro, una disciplina conformada a partir del uso simultáneo de diferentes sistemas semióticos (escenografía, gestualidad, cinésica, proxemia, vestuario, efectos sonoros, etc.) que son capaces de generar un complejo significado simbólico que es necesario descifrar. Todo en un escenario es significado; todo es significativo, y ese es el motivo por el que los emblemas, que son una forma compleja e ingeniosa de significado en sí mismos, tuvieron un impacto tan importante en la concepción dramática. La esencia visual de los emblemas, que siempre ocultan un sentido conceptual, encontró un marco adecuado de expresión en los escenarios auriseculares. Fernando Rodríguez de la Flor (1995, 75-76) señaló la gran influencia que la literatura emblemática tuvo en la dramaturgia de la España de la época. En realidad, él concibe el teatro barroco como un emblema viviente puesto en movimiento:

El espacio teatral en los siglos XVI y XVII abunda en elementos heredados de la tradición abierta por Alciato. [...] Y es que todo, desde el texto a los personajes, particularmente en las alegorías de los autos sacramentales, gozaba de una perspectiva emblemática. El título, próximo a la concisión del lema o motto; la escenografía, que utiliza objetos a modo de símbolos, y por último el propio texto, concebido como una suerte de desarrollo o declaración de los dos anteriores elementos, hacen del teatro barroco un auténtico emblema vivo y puesto en acción, en el que no faltan temas, imágenes, sentencias y glosas sacadas de la propia tradición emblemática.

Los emblemas pueden ser empleados en una obra teatral de tres maneras diferentes: 1) usando un emblema existente; 2) a través de un proceso de intertextualidad que implica no solo libros de emblemas sino también diferentes fuentes literarias y artísticas usadas en la creación de emblemas (pinturas, la poesía de Ovidio, fábulas, etc.); y 3 ) por medio de un proceso creativo acometido por un dramaturgo que genera sus propias interpretaciones simbólicas y que se podría decir que crea un nuevo emblema. Un ejemplo significativo de esta última posibilidad son los autos sacramentales, que realmente pueden con- 
siderarse como emblemas en movimiento debido a la altísima carga alegórica con la que se configuran. En otras palabras, como Ignacio Arellano $(1997,419)$ explicó al tratar sobre el teatro de Cervantes, la inclusión de emblemas en el argumento de estas obras pudo hacerse tanto en un nivel textual como en la manera en la que los dramaturgos concebían una escena concreta, por lo tanto, solo como una referencia incluida en el diálogo o como una imagen que el público veía sobre el escenario.

En los últimos años, en diversos estudios se ha reflexionado sobre la manera en la que el arte dramático se aprovechó de la literatura emblemática (Revueltas 2003) y se ha demostrado la influencia y la presencia de emblemas, de manera más o menos explícita, en obras de Cervantes (Arellano 1997), Calderón de la Barca (Mariscal 1981; Cardona 1996; Waltaus 2001; Arellano 2000 y 2002), Tirso de Molina (Smith 1985; Restrepo 1995; Oteiza 2001; Waltaus 2001), Antonio Mira de Amescua (Cull 2000) y otros dramaturgos como Luis de Belmonte, Agustín Moreto y Antonio Martínez de Meneses (Zuzankiewicz 2013). Por supuesto, la crítica también ha prestado atención a la obra de Lope, tanto en el conjunto de su producción (Brito Díaz 1996) como específicamente en su teatro (Dixon 1993).

Cuando planeé este trabajo quería comprobar esta influencia y presencia a finales del siglo XVI, que es un periodo bastante desatendido a este respecto por la crítica. Siendo un campo tan vasto, me voy a centrar en la producción de Lope de Vega en ese momento y, dentro de ella, en un subgénero específico, uno que consideré que habría sido más fácilmente influenciado debido a su propia naturaleza y a su alto grado de codificación: me estoy refiriendo a la comedia pastoril que, además, conozco relativamente bien ya que a diversos aspectos de la misma he dedicado algún trabajo en los últimos años. El corpus de obras analizadas está conformado por cinco comedias: Belardo el furioso, escrita entre 1586 y 1595 (probablemente en torno a 1589), pero siempre, de acuerdo a Joan Oleza (1986, 301-303), antes que la versión conservada de El verdadero amante ${ }^{1}$. Esta fue compuesta entre 1590-1595, probablemente en torno a la primera de dichas fechas según el propio crítico (303-305). Al mismo arco temporal, correspondiente a la estancia del Fénix en Alba de Tormes (1591-1595), pertenece Los amores de Albanio y Ismenia (Morley y Bruerton, 1968, 44 y 76-77). Por su parte, La pastoral de Jacinto se data entre 1595 y 1600 (228 y 46). Por último, estaría La Arcadia, fechada en torno a 1615 (Crawford, 1907; Morley y Bruerton 1968, 285-286). Me centro, por consiguiente, en un arco temporal de aproximadamente un cuarto de siglo, esto es, comprendido entre 1589-1615.

Deben tenerse en cuenta un par de premisas antes de proceder con el análisis. En primer lugar, es necesario señalar que intentar establecer un emblema

${ }^{1}$ Estas obras tempranas fueron reescritas por Lope aproximadamente dos décadas más tarde para ser publicadas. Para las características de la dramaturgia del joven Lope, véase Oleza (1986). 
específico como la fuente directa de una escena concreta es una tarea arriesgada, cuando no imposible, a pesar de que en algunas ocasiones la crítica ha tratado de hacerlo con mayor o menor éxito. Además, la mayoría de las veces los emblemas representan motivos, lugares comunes que se repiten de manera habitual. Los aproximadamente seis mil libros de emblemas que se imprimieron por toda Europa $^{2}$ son una muestra palpable del enorme éxito que tuvo el género y de cómo influyó a todo tipo de artistas e intelectuales durante los siguientes dos siglos.

Duncan Moir, por ejemplo, fue un poco más allá cuando defendió que algunos emblemas incluidos en los Emblemas morales de Sebastián de Covarrubias (1610) inspiraron a Lope no solo la delineación de una escena, sino que fueron su motivación a la hora de escribir un puñado de obras importantes como Fuenteovejuna (Imagen 1) ${ }^{3}$, El villano en su rincón (Imagen 2$)^{4}$, La villana de Getafe o El perro del hortelano. Moir estaba tan convencido de la relación de dependencia entre el texto de Lope y los emblemas de Covarrubias, especialmente en el caso de la primera de las obras mencionadas, que se aventuró a afirmar lo siguiente:

I grant that, if Fuenteovejuna was, in fact, written by 1609 , the year in which, on the 29th of August, the censura of the Emblemas morales was signed, then Covarrubias might have been thinking of the play when he devised that emblem, but such an early date for the play is unlikely (Moir 1971, 545).

La segunda premisa es que, sorprendentemente, la representación del convencionalismo bucólico, a pesar de tratarse de una temática perfectamente codificada y reconocible debido a su éxito y a su difusión poética y novelística, no es tan abundante como pudiera suponerse a priori. La naturaleza constituye, por supuesto, el marco en el que buena parte de las escenas de estos emblemas se ubican, pero la concepción pastoril está casi siempre ausente.

He limitado mi búsqueda a aquellas colecciones que fueron publicadas antes o en torno a los años en los que Lope compuso las piezas objeto de estudio en este trabajo. Estaríamos hablando de los emblemas de Alciato, los Triumphos morales de Francisco de Guzmán (1565), los Emblemas o Empresas morales de Juan de Borja (1581), los Emblemas morales de Juan de Horozco y Covarrubias (1589-1591) y los Emblemas moralizadas de Hernando de Soto (1599).

${ }^{2}$ El cálculo fue realizado por Daly (1998). Yo cito a partir de Cull (2000, 128, nota núm. 5).

${ }^{3}$ Se trata del emblema número 97 de la tercera Centuria. Moir fue capaz incluso de trazar vínculos viables y lógicos con otros dos emblemas (el número 45 de la tercera Centuria y el 64 de la segunda) que podrían haber inspirado al dramaturgo a incluir otra serie de escenas en el argumento, animándole a elaborarlas con varios grados de conceptualización.

${ }^{4}$ Es el emblema 70 de la tercera Centuria. 
Puesto que muchas o tal vez todas estas comedias fueron retocadas e incluso reescritas por Lope unas décadas más tarde con el objetivo de prepararlas para su publicación, he tomado en consideración también los Emblemas morales de Sebastián de Covarrubias Horozco (1610), un libro, como mencioné anteriormente, que Duncan Moir defendió que Lope conoció y usó; hasta propuso una posible relación personal entre los dos autores. He manejado además un par de populares libros extranjeros que pudieron haber tenido un impacto, directo o indirecto, en nuestro comediógrafo. Estos son el Symbolicarum quaestionum de Achille Bocchi (1574) y la Iconología de Cesare Ripa (1593).

Dicho todo esto, mi objetivo no ha sido intentar encontrar una relación directa entre un emblema y una escena específica, sino, en lugar de eso, una conexión entre ambos elementos basada en una suerte de espíritu compartido, de un «modo de ver» análogo de origen social y la manera en la que se figurativiza «lo visto», de una esencia común o idéntica a la hora de imaginar una situación y, debido a ello, se ha intentado trazar una influencia posible y argumentable. De lo que estamos tratando aquí es de campos expresivos, que pueden definirse como el medio conceptual por el que una realidad concreta puede ser imaginada y, en este caso, visualmente construida. El «Zeitgeist»o «espíritu del tiempo» de aquella época guio la concepción de ciertos espacios de un modo por el que podían ser (re)creados a través de formulaciones plásticas convencionales. Considero que la cuestión no es fijar fuentes referenciales difíciles de probar, sino encontrar intertextos; en otras palabras, conceptos y nociones interrelacionados, interconectados.

La influencia de las artes visuales en Lope fue importante. Como ya he demostrado en varios trabajos anteriores (Sáez Raposo 2016 y 2017b), cuando el Fénix delineó los espacios dramáticos por los que los personajes de estas obras deambulan, siguió una técnica similar a la del perspectivismo lineal que los pintores estaban probando e implementando desde el Quattrocento italiano y que fue perfeccionada y llevada a su máxima expresión en el siglo XVI por medio de la experimentación con las distancias entre los diferentes elementos incluidos en el cuadro y también entre este y su observador.

Aunque algunos análisis se han centrado en señalar la influencia implícita que los emblemas tienen a nivel textual, esto es, en la mención de imágenes simbólicas tomadas de libros de emblemas que fueron usadas en una suerte de ejercicio ecfrástico académico, el asunto no está ni mucho menos agotado. La mayoría de las veces se ha prestado atención principalmente al simbolismo relacionado con el color, con la mitología o con los elementos vegetales $(\mathrm{Cu}-$ pido, el ave fénix, las arpías, la palmera, el laurel, la unión entre la vid y el olmo, entre la hiedra y el muro, etc.). Pero también es posible encontrar otros que no son tan obvios, que aparecen ocultos entre líneas, implícitamente, de un modo sutil. Un buen ejemplo de ello podría ser la repetida referencia a una serpiente que se pisa. Se trata, en realidad, de un locus virgiliano, ya que aparece reflejado en la Égloga III del poeta romano cuando el personaje de Dame- 
tas advierte a su compañero Menalcas del peligro que suponen las serpientes escondidas entre las hierbas para los que, como ellos, desempeñan labores de pastoreo: "Qui legitis flores et humi nascentia fraga, / frigidus, o pueri!, fugite hinc, latet anguis in herba» (vv. 92-93). Es, por consiguiente, un caso extraordinario, ya que en él descubrimos que los emblemas ya se están nutriendo de una tradición pastoril centenaria.

En el tercer acto de Amores de Albanio y Ismenia, el protagonista, Albanio, anima a Frondoso a ir tras Ismenia, el personaje principal femenino, justo después de que esta se marche, pero él se muestra temeroso, ya que lo ha hecho enfadada:

\section{Vase Ismenia.}

ALBANIO ¡Oh, pasos apresurados cuyas estampas bendigo! Sin duda parte enojada. Ve, Frondoso, ve tras ella.

FRONDOSO Va herida y temo ofendella como víbora pisada (Vega 1993, 634)5.

Solo por mencionar otro ejemplo, podemos referir el que aparece en Belardo el furioso, cuando Jacinta, aprovechando un momento de descuido del protagonista, huye y se dirige hacia el bosque. Como él es incapaz de encontrarla tras seguirla, piensa, debido a su desbordante imaginación provocada por su locura, que ha muerto tras ser mordida por una serpiente:

$\begin{array}{ll}\text { BELARDO } & \text { Fui tras ella y no la vi, } \\ & \text { de donde alguna culebra } \\ & \text { que ella pisó, colegí } \\ & \text { que cortó la sutil hebra } \\ & \text { de la vida que perdí. } \\ & \text { Murió Jacinta sin duda... (Vega 1965a, 97b). }\end{array}$

En su Iconología, Cesare Ripa incluye un emblema que representa la imagen icónica del «Peligro» (Imagen 3), que está personificado como un joven caminando por un sendero de hierba fresca y que acaba de pisar una serpiente que se revuelve y le muerde fieramente en una pantorrilla. Él camina apoyado en un cayado, a su lado aparece un precipicio, en la esquina superior derecha se ven rayos cayendo del cielo y, en el otro lado, hay un curso fluvial.

En mi opinión, el propio núcleo argumental de La pastoral de Jacinto puede vincularse con otro emblema encontrado en el libro de Sebastián de Covarrubias Horozco, aquel que representa a una mona que se mira en un es-

\footnotetext{
${ }^{5}$ En las citas, como sucede en este caso, el énfasis siempre será mío.
} 
pejo que sostiene en una mano y que incluye el lema «Ninguna está a disgusto con su propio aspecto» ${ }^{6}$, tópico tomado del Ars amandi de Ovidio (Imagen 4). La trama de esta obra se construye en torno al motivo del doble. A causa de sus excesivos celos, Jacinto está convencido de que Frondelio es un rival amatorio con sus mismas características, virtudes e incluso idéntico nombre. En un momento climático de la historia, al final del Acto II, tiene que enfrentarse a él, y en esta perturbadora situación literalmente menciona la imagen que constituye el emblema:

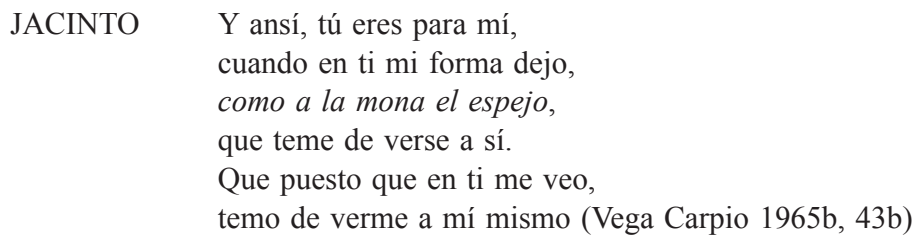

Como mencioné con anterioridad, contrariamente a lo que pudiera pensarse, no es fácil encontrar emblemas que representen los propios motivos pastoriles. El único que he podido localizar en el corpus analizado es el llamado $\mathrm{La}$ verdad revelada a los pastores que aparece en el libro de Achille Bocchi (Imagen 5$)^{7}$. A pesar de que el concepto que hay detrás de él no tiene nada que ver con los argumentos de nuestras obras, es interesante para nosotros porque podemos encontrar un arquetípico espacio rural en el que un pueblo puede verse en la distancia. Y la sensación de profundidad sí es una constante en este corpus. Lope crea verbalmente un espacio dramático latente que desborda el escenario mediante la diseminación de información, de pequeños detalles que deben ser recopilados por el público y usados para (re)crear en sus mentes un lugar de acción específico. En muchas ocasiones, genera una sensación de tridimensionalidad a través de percepciones frecuentemente relacionadas con el campo auditivo, sensación que se realza por medio de los gestos y las distancias entre los actores.

No relacionado específicamente con pastores sino con campesinos y su labor y, lo que es de interés para nuestro propósito, con espacios organizados en niveles diferentes, hay varios emblemas incluidos en los Emblemas morales de Sebastián Covarrubias Horozco. En uno de ellos, con el lema «Alternis facilis labor» o «El trabajo es sencillo para quienes se turnan» (Centuria III, Emblema 50), podemos ver a un campesino arando un campo adyacente a una tierra en barbecho y, en la lejanía, una iglesia que indica la presencia de un

\footnotetext{
${ }^{6}$ Este emblema aparece erróneamente registrado, en la Centuria I, con el número 98 cuando realmente es el 96 dentro de la serie.

${ }^{7}$ Dice el lema: «La propia verdad sobresale hasta el punto de que aparta a la vana apariencia». En la parte superior del grabado se consigna el término Aletheia=Verdad («Veritas» en latín).
} 
pueblo (Imagen 6). Mucho más cercano está el pueblo, en esta ocasión representado claramente, en el emblema que incluye el lema «Lassat sed juvat», que significa «Cansa, pero deleita» (Centuria I, Emblema 33), donde puede verse un grupo de campesinos cosechando un campo de trigo (Imagen 7).

Los espacios en las obras de Lope están surcados por innumerables senderos. Tenemos la sensación de estar mirando a personajes en movimiento, que siempre se encuentran con alguien que viene de algún lugar y, a su vez, ellos se marchan a otro sitio diferente. A veces, debido a que van sin rumbo fijo buscando un lugar apartado para lamentarse de sus desdichas amorosas; otras veces porque están en pleno desempeño de sus labores de pastoreo. Este incesante deambular de pastores es, según la opinión de Azorín, inherente a la idiosincrasia de España ${ }^{8}$. Alciato incluye un emblema en su Emblematum liber (Imagen 8$)^{9}$ que representa al dios Mercurio sentado y señalando a un caminante el sendero apropiado que hay que escoger en un cruce de caminos.

En la edición del libro (Imagen 9) que llevó a cabo, Bernardino Daza Pinciano (Los emblemas de Alciato traducidos en rimas españolas, publicado en Lyon por Guillaume Roville y Macé Bonhomme en 1549) ${ }^{10}$ traduce el lema como «Que hemos de ir por donde Dios nos llama». En otras palabras, desde un punto de vista simbólico, estamos siempre encontrando múltiples y diversos senderos delante de nosotros y es esencial elegir el que mejor se ajuste a nuestras necesidades. Como los pastores en las obras de Lope, siempre estamos yendo de un lugar a otro y nuestro destino, con sus altibajos, está ligado al sendero que decidimos recorrer. Además, Sebastián de Covarrubias Horozco incluye una variante de este motivo (Imagen 10) ${ }^{11}$ con una declaración moral más evidente, ya que defiende la idea aristotélica de que la virtud se encuentra en el término medio, en este caso, usando el valor metafórico de tres senderos diferentes, uno que atraviesa un valle, otro una montaña y el último y más recomendable, el señalado por Mercurio, el intermedio, que pasa por una colina.

El contexto fantástico, idealizado e incluso semi-mitológico en el que la acción dramática transcurre permite la inclusión de la Esfinge como un personaje en Los amores de Albanio y Ismenia. En el Acto segundo, la protagonista, tratando de evitar los requiebros amorosos que le dedican tanto Vireno como Ascanio, les solicita, a modo de prueba, que vayan a lo alto de una montaña a encontrar una cueva ubicada en un punto de muy difícil acceso, que es, precisamente, donde vive una Esfinge similar a la de Tebas y que, como aquella, plantea a quien se acerca un acertijo que hay que resolver si se quiere acceder al agua milagrosa que protege. Con este ser fantástico, Lope no solo presenta

\footnotetext{
8 «El genio de España no podrá ser comprendido sin la consideración de este ir y venir de los rebaños por montañas y llanuras» (Azorín 1939, 68).

9 El emblema número VIII.

${ }^{10}$ Existe una edición moderna a cargo de Rafael Zafra (2003).

11 Centuria III, Emblema número 46.
} 
a un personaje impactante, sino también un espacio peligroso, inquietante y emocionante, enfatizado por la gestualidad de los actores, sus movimientos y las distancias que guardan entre ellos y con el ser mítico. En un momento dado, el monstruo sale de su cueva. La acotación dice «... sale la Esfinge, con rostro de mujer y cuerpo de león, en pie». No es difícil suponer que Lope, $\mathrm{y}$, claro está, el público (porque para que la comunicación surta el efecto deseado es necesario que los factores que intervienen en la misma compartan el mismo código, es decir, el mismo «modo de ver»), tendrían en mente la estampa de la Esfinge incluida por Alciato en su libro (Emblema CLXXXVII), en la que podemos encontrar a una criatura con la cara de una doncella, las alas de un ave $^{12}$, y las patas traseras de un león (Imagen 11).

Con este monstruo mitológico se simbolizaba la necedad y la ignorancia. Eso sí, no se representa en una cueva, sino en un terreno escarpado rodeado de ruinas. En la edición de Daza Pinciano podemos ver (Imagen 12) lo que parece un castillo o incluso un pueblo pequeño a lo lejos. Pero las cuevas aparecen en otros emblemas, y siempre con una connotación peligrosa, negativa y maligna. El valor simbólico, metafórico e incluso psicoanalítico de la cueva, en muchas ocasiones ligado con el concepto religioso de pecado, es claro, y se pueden trazar paralelismos entre nuestra escena y algunos otros emblemas hallados, por ejemplo, en los Triumphos morales de Francisco de Guzmán, específicamente, en el capítulo dedicado al Triunfo de la voluntad. En este primero (Imagen 13), no hay lema, pero la subscriptio o poema incluido en él señala que está simbolizando un pecado capital, la «Lujuria», representado por una mujer que agarra a un hombre y lo introduce por la fuerza en una cueva que es, en realidad, la mismísima entrada al Infierno. En otro (Imagen 14), del mismo autor y que representa un pecado diferente, la «Ira», el paralelismo con la obra de Lope es todavía más obvio, ya que podemos encontrar a una bestia muy similar a la Esfinge pero, en este caso, se trata de un tigre rampante que sale de una cueva y arrastra a un hombre a su interior (de nuevo, al Infierno) para condenarlo por toda la eternidad.

Por otra parte, soy consciente de que estamos tratando con un género totalmente codificado, estilizado, sublimado, como podemos ver en este emblema (Imagen 2) incluido en el libro de Covarrubias Horozco y tomado directamente de las églogas de Virgilio, donde aparece un pastor tocando su rabel apoyado en un pino con su rebaño de ovejas en las inmediaciones. El tema, extraído directamente de las églogas de Virgilio, incluye el lema «Dios hizo esos momentos de descanso para nosotros». Pero también estoy seguro de que hubo una influencia bidireccional entre disciplinas artísticas. Por lo tanto, la literatura pastoril, que fue tan popular en Europa durante la primera mitad del siglo XVI, pudo influir a Alciato a la hora de concebir la imagen de algunos emble-

12 Ripa también señala que esta criatura posee dos grandes alas en la espalda. 
mas y tal vez, décadas después, cuando el género había perdido su empuje dramático a favor de su versión en la forma de novela, la dirección de la influencia pudo cambiar, y su libro pudo inspirar también a dramaturgos como Lope que estaban intentado recuperarlo para los escenarios. Y, además, estoy convencido de que los emblemas tuvieron un impacto no solo en la forma en la que dichos dramaturgos esbozaron la composición de las escenas, sino también en la manera de interpretar de los actores. Como pasó con el manierismo en pintura, la representación de ciertas situaciones en emblemas tendría una influencia en el modo en el que los actores y las actrices hicieron lo propio sobre un escenario, especialmente si consideramos la carencia de tratados de interpretación actoral. Las escenas con pastores, tanto hombres como mujeres, quejándose en solitario sobre sus cuitas amorosas es una constante. Un ejemplo excelente puede encontrarse en el Acto I de La pastoral de Jacinto, cuando Flórida sugiere que Albania busque la ayuda de un pastor «sabio y encantador» que con su hechizo evitará que la última se enamore de Jacinto reencarnado. Mientras el primero abandona el escenario, Albania se queda en el bosque donde está transcurriendo la escena esperándola, cerca de una fuente, reflexionando sobre la naturaleza y las consecuencias del amor:

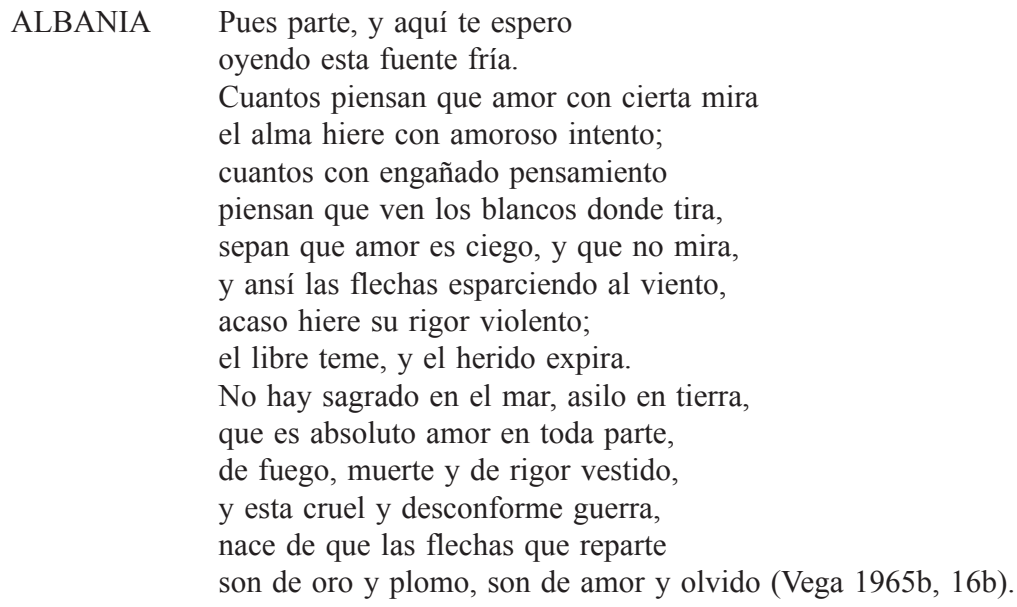

Creo que la similitud con este emblema de Acchille Bocchi (Imagen 15) va más allá de la mera casualidad y requiere poco comentario adicional.

Esta digresión sobre el impacto de los emblemas en el teatro del primer Lope no estaría completa sin la mención de la opción definitiva y más compleja en la que estos podían presentarse sobre el escenario. Me estoy refiriendo a la creación por parte del Fénix de emblemas vivos o, como podríamos definirlos, emblemas tridimensionales. Se trata de escenas planeadas por él, con toda probabilidad, teniendo en mente o estando bajo la influencia consciente o inconsciente del género emblemático. En otras palabras, no es que Lope estuvie- 
ra pensando en un emblema específico a la hora de crear una escena determinada, sino que el alma, la esencia del género eran tan poderosas en el panorama cultural del momento (afectando, como sabemos, a otras artes como la pintura), que no creo equivocarme al afirmar que hay escenas de estas obras que responden al patrón visual que define lo que es un emblema. Es lo que en su día Víctor Infantes describió como «un emblema sin emblema». Martin White $(1998,10)$, refiriéndose al teatro isabelino, afirmaba que «... playtexts frequently imply that a stage image comprising a single figure or a group has been created in the form of a verbal and pictorial tableau that embodies particular relationships or makes abstract themes concrete...».

Podemos traer a colación un ejemplo de esta práctica en Lope tomado de la Jornada primera de La pastoral de Jacinto. Sabiendo que Flórida y Albania pueden verse desde la distancia, Frondelio finge ser un pastor llamado Jacinto que supuestamente está perdidamente enamorado de Albania. Frondelio declara que se ha metamorfoseado en una planta que ha tomado el nombre de él (el jacinto) y, después de eso, ha sido resucitado por el dios Apolo. Frondelio aparecería con aspecto severo y estático mientras que Doriano fingiría estar asombrado y se arrodillaría ante él. Las dos mujeres quedan asombradas ante tal visión:

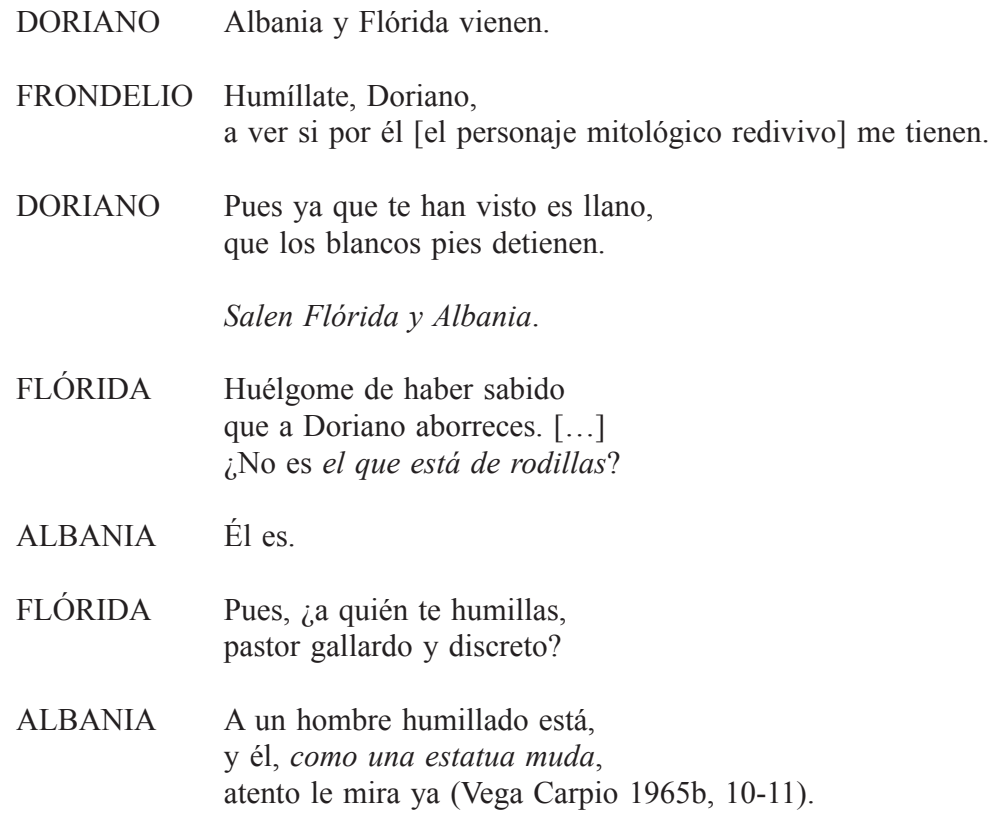

El segundo ejemplo lo extraemos de La Arcadia. En una de las escenas más sugerentes de toda la obra, justo al comienzo de la Jornada primera, la pastora Anarda pronuncia un soliloquio en el que revela su inquietud ante la posibilidad 
de asegurar el amor de Anfriso, ahora que Belisarda, la protagonista, ha sido prometida a Salicio. Y lo hace mirándose como en un espejo en el agua de un río:

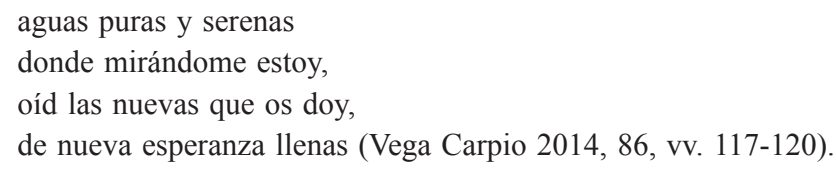

La existencia de una serie de escenas en las que dicho río se muestra como una realidad tangible (Anarda ha de cruzarlo para reunirse con Anfriso y Silvia a la vista del público -vv. 141-148-, o un enajenado Anfriso arroja al gracioso Cardenio a sus aguas y, como se especifica en una acotación implícita, sabemos que no solo responde aparentemente desde el agua, sino que también sale de escena nadando -vv. 2845-2849-) parecería requerir un espacio al aire libre de naturaleza cortesana. Pienso en un jardín adyacente a un río, como fue el escenario de El premio de la hermosura, del propio Lope, y el de El caballero del Sol, de Luis Vélez de Guevara, representadas, en 1614 y 1617 respectivamente, en el parque de la villa de Lerma en escenarios levantados a lo largo de las orillas del río Arlanza. El vellocino de oro, también de Lope, y La gloria de Niquea, de Juan de Tassis, conde de Villamediana, fueron estrenadas en circunstancias similares, en esta ocasión, en 1622 en el Jardín de los Negros y en el Jardín de la Isla, ambos ubicados en el Real Sitio de Aranjuez, donde la presencia del Tajo es decisiva ${ }^{13}$. Es decir, lo que en un principio podría interpretarse como una (re)creación imaginaria de ese río a partir del diálogo y la gestualidad de la actriz, como un recurso típico de la desnudez escénica de los teatros públicos de la España aurisecular (el denominado decorado verbal), se va revelando según avanza el argumento como una más que plausible existencia real de dicho río.

Aunque nada tiene que ver con el argumento de La Arcadia desde un punto de vista temático, ni con las circunstancias particulares por las que atraviesa Anarda, Andrea Alciato incluye en su libro un emblema (número LXIX) denominado Filautía («Amor a sí mismo») en cuya imagen vemos a Narciso mirando ensimismado su reflejo en las aguas de un río (Imagen 16). Como señalo, el trasfondo es muy otro, pero el valor conceptual que carga la imagen es análogo: el recogimiento de un personaje absorto en el sentimiento amoroso que le embarga. Incluso considero que sería posible trazar algún vínculo entre la esencia del texto que acompaña a la imagen y el papel de Anarda en la trama de la obra, ya que su interés por separar a la pareja de enamorados en beneficio propio (puesto que está enamorada de Anfriso) constituye uno de los motores principales de la acción dramática. Alciato achaca a la «filautía» el

${ }^{13}$ Sobre el más que probable montaje palaciego de La Arcadia, véase Ferrer Valls (1995), que proporciona los ejemplos citados en la villa de Lerma, y Sáez Raposo (2017a). 
descarrío de muchos hombres sabios debido a que, y esto es lo relevante para nosotros, se dejan arrastrar por sus propias fantasías:

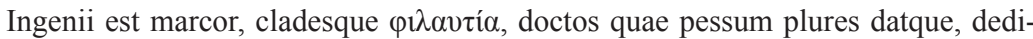
tque viros: qui veterum abiecta method, nova dogmata quaerunt, nilque suas praeter trader phantasias. [Es la «filautía» marchitez y plaga del ingenio, que arruina y ha arruinado a muchos hombres doctos que, despreciando el método de los antiguos, buscan nuevos dogmas y no transmiten sino sus propias fantasías $]^{14}$ (Sebastián 1985, 104).

En su edición del libro del humanista milanés, Bernardino Daza Pinciano incluía una variante del grabado (Imagen 17). Su traducción del texto que lo acompaña en forma de octava real es la siguiente:

Por ser, Narciso, tú de ti contento, en la flor de tu nombre estás mudado.

Es falta y manquedad de entendimiento

ser uno de sí mesmo aficionado.

El cual amor a varones sin cuento

en grande ceguedad ha derrocado,

porque dejadas las antiguas vías

sólo quieren seguir sus fantasías.

Las propias fantasías de Anarda, estimuladas por la circunstancia del matrimonio que ha impuesto a Belisarda su padre, son las que la incitan a ir tejiendo toda una serie de enredos con el objetivo de afianzar donde verdaderamente importa, en los sentimientos, el distanciamiento forzoso que ha sido dispuesto contra la voluntad de la pareja. No obstante, como en tantas ocasiones en las que se produce la influencia mutua entre artes de naturaleza diversa, creo que la impronta poética de la imagen es lo esencial aquí, y no tanto el asunto específico que representa. Lo visual se impone a lo textual.

Por último, en Belardo el furioso podemos encontrar dos emblemas vivientes presentados casi de forma consecutiva, uno al final de la Jornada primera y el otro al inicio de la segunda. Los dos cuentan con la participación de los mismos personajes (el principal, Belardo, y su amigo Siralbo) y desarrollan el mismo sentimiento sublimado: la desesperación.

En el primero, Belardo solicita a su compañero que vacíe su zurrón para quemar todos los objetos, los regalos, que Jacinta, su amada, le dio (cartas de amor, una cinta verde, un mechón de su cabello, un pequeño retrato, etc.), porque haciendo esto intentará olvidarla para siempre. En la jornada siguiente, que se desarrolla unos meses después, para reafirmar su determinación pedirá a Siralbo que entierre otro retrato de ella (tenemos una acotación que indica que este cava en el suelo con una daga) y prepara un epitafio para esta tumba

\footnotetext{
${ }^{14}$ La traducción es mía.
} 
metafórica y, por extensión, para su relación de amor con Jacinta: «Aquí yacen sin morir, / mi lealtad y tu hermosura». Por consiguiente, tenemos aquí un lema (el epitafio), una imagen (viviente en este caso, una tableau vivant) y una inscripción constituida por el diálogo.

Si se me permite el coloquialismo, tengo la impresión de que únicamente estamos viendo la punta de un inmenso iceberg oculto bajo la superficie de muchas realidades visuales que sirvieron de inspiración en el momento de construir los textos dramáticos del Siglo de Oro español. Sospecho que aún queda mucho más por descubrir en lo referente a la influencia de la cultura emblemática en la concepción de un buen número de escenas de nuestro repertorio teatral clásico. Y, como espero haber demostrado a lo largo de este artículo, no me refiero únicamente a referencias textuales de un personaje determinado, presentado de forma más o menos explícita, relativas a conceptos extraídos o explicados en este o aquel emblema, sino a verdaderas improntas visuales inspiradas por uno o varios de ellos y materializadas sobre el escenario en la forma de imágenes concretas. Es un asunto fascinante, como hemos tenido ocasión de comprobar, pero, a la vez, que plantea un reto complejo: el de poder trazar vínculos entre algunas realidades tangibles y otras etéreas, el de ser capaces de capturar «el modo de ver» de un artista como Lope, en este caso, que está condicionado por el de la sociedad a la que pertenece; esto es, apuntar la posibilidad de establecer nexos entre referencias textuales directas e improntas visuales o nociones dependientes de ellas pero ancladas en la imaginación del artista. En otras palabras, entre el texto literario y el espectacular, una fusión necesaria, no lo olvidemos, para la configuración del texto dramático, que es siempre el fin último que el dramaturgo tiene en mente cuando se embarca en la creación de una obra teatral.

Creo que estamos en disposición de aceptar que los emblemas jugaron un papel importante en la concepción y creación del espacio dramático e incluso en la de la escenografía empleada en las obras escritas en España durante el final del Renacimiento y el Barroco, probablemente mucho más de lo que habíamos considerado hasta ahora. Tenemos, por consiguiente, ante nosotros un interesante, vasto y productivo campo de investigación. Duncan Moir concluye su citado artículo otorgando a los Emblemas morales de Sebastián de Covarrubias un papel crucial como fuente de información variada y heterogénea que podía ser usada por autores, como hizo Lope, cuando buscaban temas, recursos y concretizaciones visuales que pudieran ayudarles a dar forma a sus historias:

If the theories which I have expressed in this study are well-founded, then it is probable that the Emblemas morales of Covarrubias became, like the Officina of Joannes Ravisius Textor, one of the commonplace books and sources of general information, mythology and iconology to which Lope de Vega made constant reference as he wrote in various works (Moir 1971, 546). 
La afirmación puede ser ampliada a otras colecciones de emblemas, empezando por la de Alciato, y a otros dramaturgos de aquel tiempo.

\section{ILUSTRACIONES}

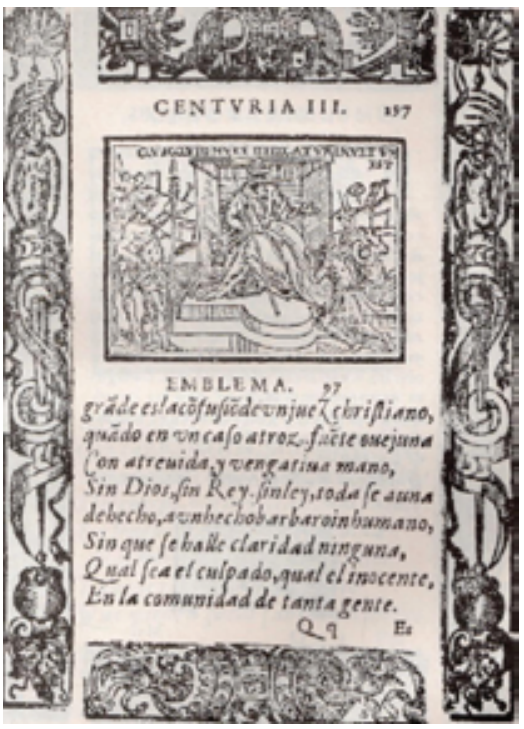

IMAGEN 1

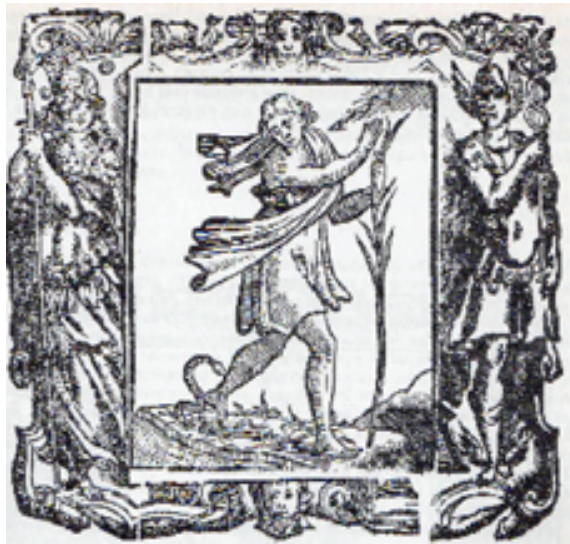

IMAGEN 3
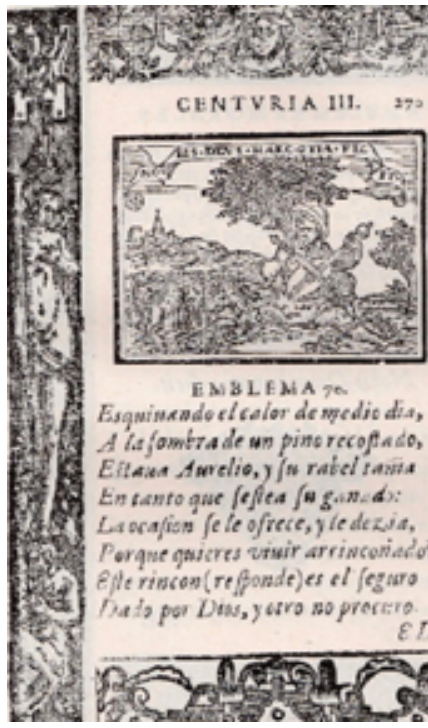

E M \& L E MA 70

Esquimendo elcolor de medio dis, A lat fombrade un pino recofitado, Elienan Anrelio, y in raidel tasid En tanto que fefiea fo gan-d : Lawafison fele ofrece, yle dezial

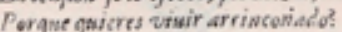
Elle rincen (reffonde)es al jogaro Dialo por Dews, y wro no presero.
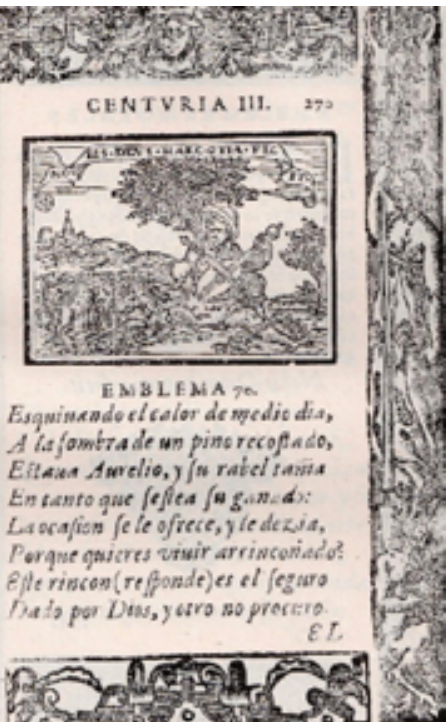

IMAGEN 2
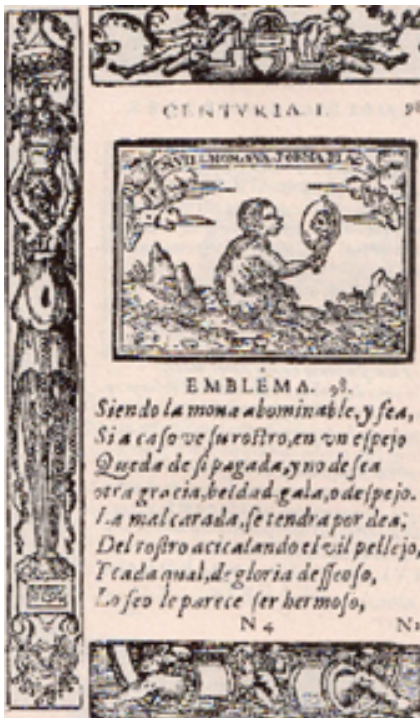

EM M LEMA.

Siendo la mowa abowinatley fea, Sia cafo ve farobiro,en on e/pejo Qurdiedeforadasynodefica otria gracia,beldad gala,odeipejo.

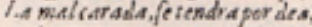
Delrofiro acicalando cieil pollejo, Teada qual,digloria defferfo, Lo feo leparese ler bermofo, $\mathrm{N}$ $\mathrm{N}$,
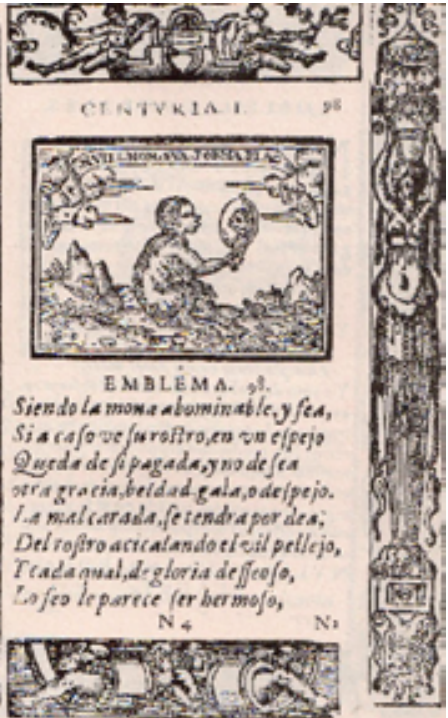

IMAGEN 4 
LIVI I.

SAT EXTAT IPSA VERITAS

VANA ABSIT OSTENTATIO.

Symb. XXXII.

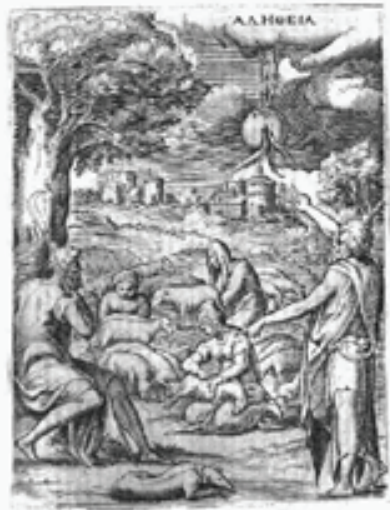

IMAGEN 5

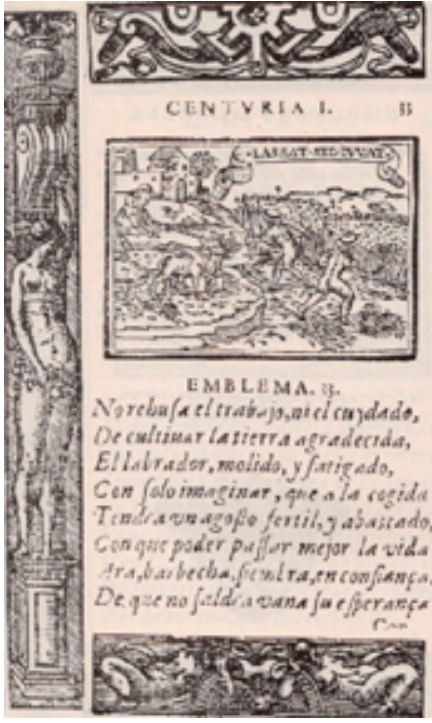

IMAGEN 7

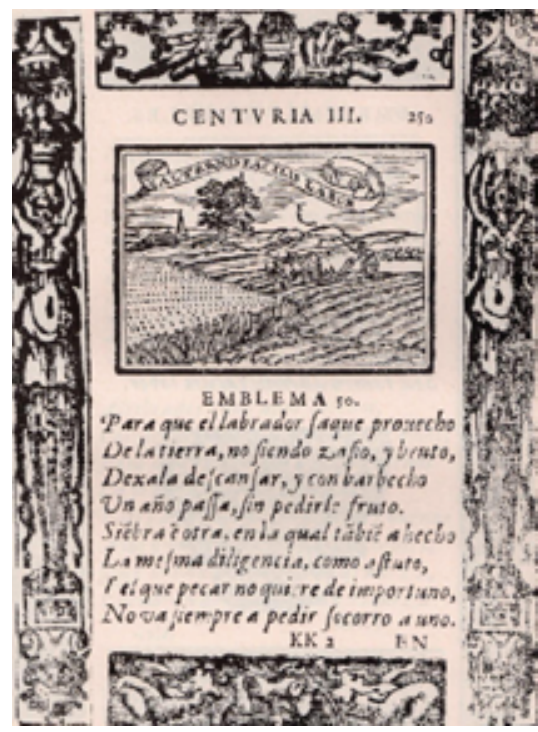

IMAGEN 6
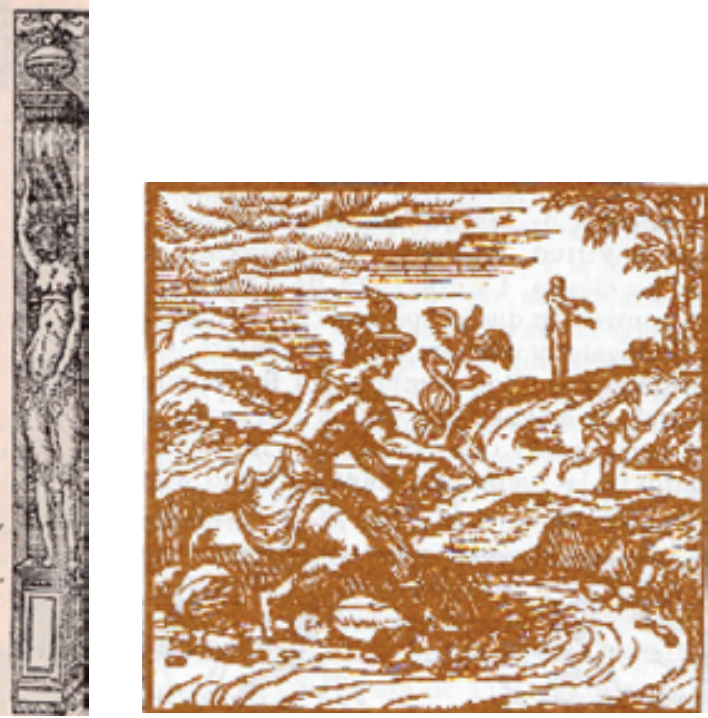

IMAGEN 8 


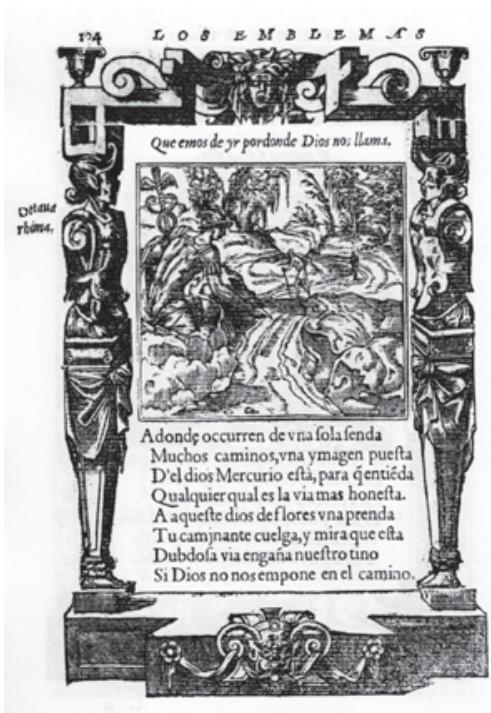

IMAGEN 9

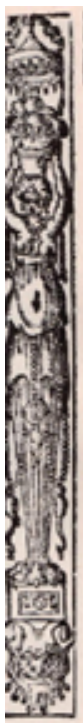

mis

CENTVRIA III, 245

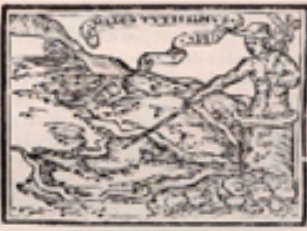

EMBLEMA As.

Caminar parel valle es pelierofo.

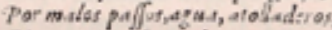

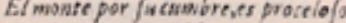
De nitacs,aire, Nicble, y whtsqueros Elcamino de conmedio to mas fabrofo Y fecuro a los banbres pafjejiras. Unciofo er el eprevero ydewaffa.

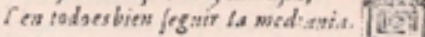

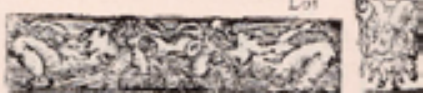

IMAGEN 10

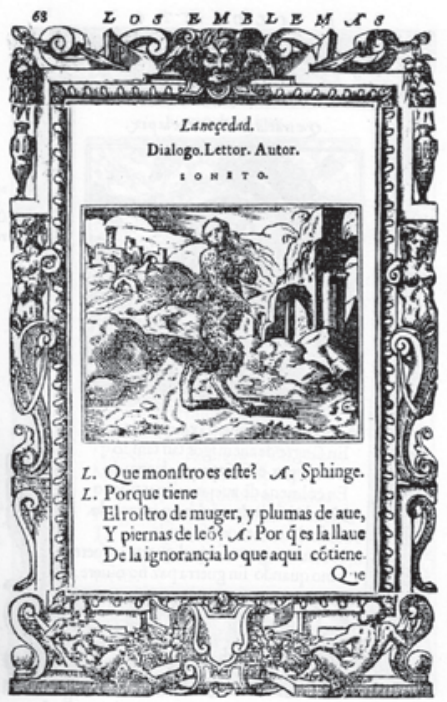

IMAGEN 12 


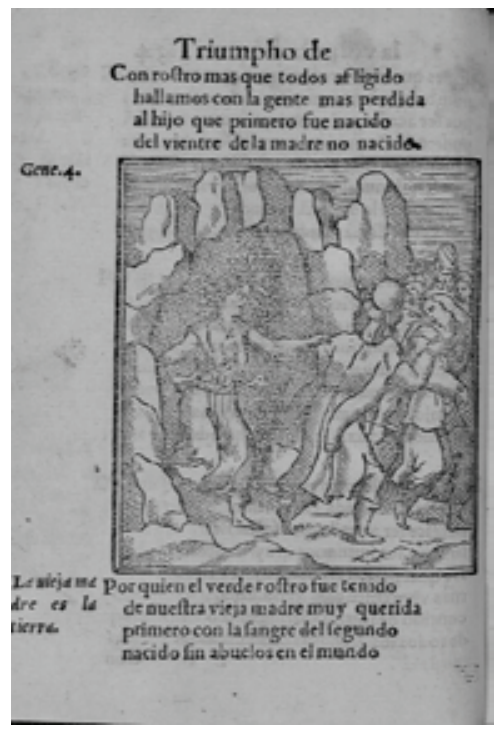

IMAGEN 13

svis

A KOR NTCOC1OSVS E5T tN OCIO.

Symb. VII.

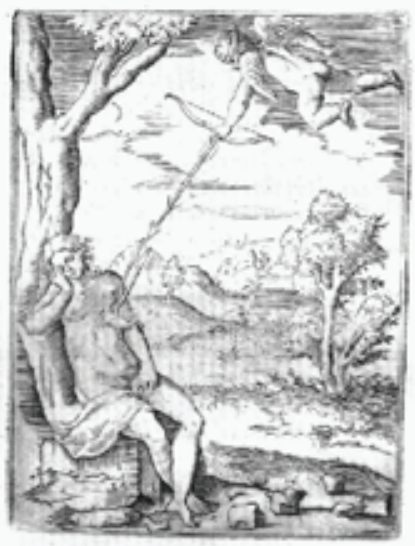

IMAGEN 15

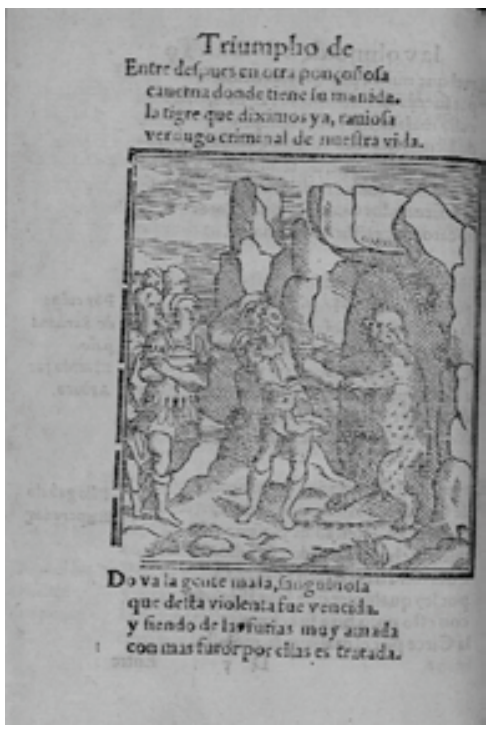

IMAGEN 14

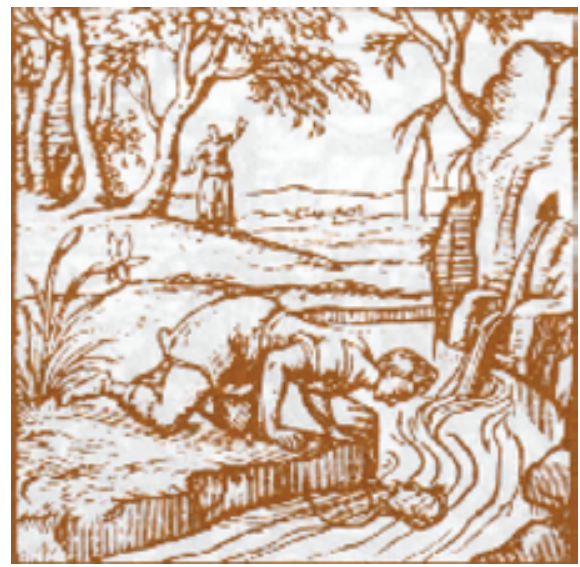

IMAGEN 16 


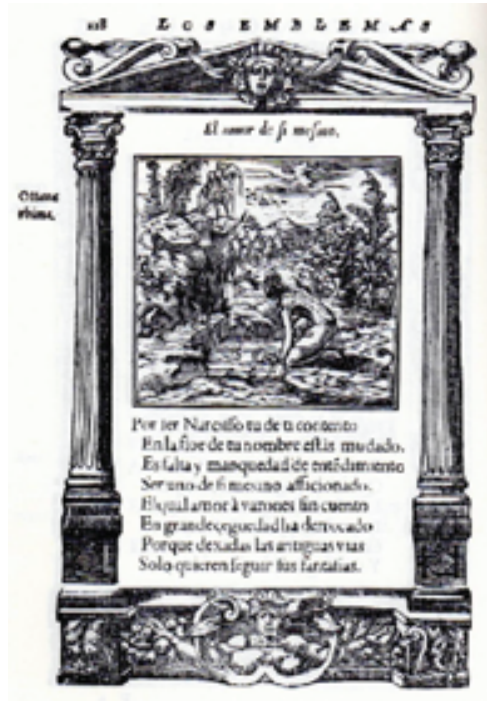

IMAGEN 17

\section{FUENTES}

Vega Carpio, Lope de. 1965a. «Belardo, el furioso». En Obras de Lope de Vega. Vol. XIII. Comedias pastoriles y comedias mitológicas, ed. Marcelino Menéndez Pelayo, 31-115. Madrid: Atlas.

Vega Carpio, Lope de. 1965b. «La pastoral de Jacinto». En Obras de Lope de Vega. Vol. XIII. Comedias pastoriles y comedias mitológicas, ed. Marcelino Menéndez Pelayo, 1-60. Madrid: Atlas.

Vega Carpio, Lope de. 1993. «Los amores de Albanio y Ismenia». Obras completas. Lope de Vega. Comedias, III. Madrid: Turner.

Vega Carpio, Lope de. 2014. La Arcadia. En Lope de Vega. Comedias. Parte XIII. ed. Ana María Porteiro Chouciño; coordinado por Natalia Fernández Rodríguez, tomo I, 47-230. Madrid: Gredos.

\section{BIBLIOGRAFÍA CITADA}

Arellano, Ignacio. 1997. «Motivos emblemáticos en el teatro de Cervantes». Boletín de la Real Academia Española 77: 419-43.

Arellano, Ignacio. 2000. «Elementos emblemáticos en las comedias religiosas de Calderón». En Calderón: una lectura desde el siglo XXI, coord. María Gómez y Patiño, 219-247. Alicante: Instituto Alicantino de Cultura «Juan Gil-Albert».

Arellano, Ignacio. 2002. «Aspectos emblemáticos en los dramas de poder y de ambición de Calderón». En Calderón 2000 (Homenaje a Kurt Reichenberger en su 80 cumpleaños. 
Actas del Congreso Internacional IV centenario del nacimiento de Calderón (Universidad de Navarra, septiembre de 2000), ed. Ignacio Arellano, vol. II, 21-34. Pamplona: Universidad de Navarra.

Azorín. 1939. Una hora de España. Madrid: Biblioteca Nueva.

Brito Díaz, Carlos. 1996. «"Odore enecat suo”: Lope de Vega y los emblemas». En Literatura emblemática hispánica. Actas del I Simposio Internacional (A Coruña, 1994), ed. Sagrario López Poza, 355-377. A Coruña: Universidade.

Cardona, Ángeles. 1996. «Estudio de los emblemas en los autos sacramentales de Calderón: El veneno y la triaca y La cura y la enfermedad». En Literatura emblemática hispánica. Actas del I Simposio Internacional (A Coruña, 1994), ed. Sagrario López Poza, 401-414. A Coruña: Universidade.

Crawford, James P. 1907. «The Date of Composition of Lope de Vega's Comedia, La Arcadia». The Modern Language Review III: 40-42.

Cull, John. 2000. «El teatro emblemático de Mira de Amescua». En Emblemata Aurea. La emblemática en el arte y la literatura del Siglo de Oro, ed. Rafael Zafra y José Javier Azanza, 127-142. Madrid: Akal.

Daly, Peter M. 1998. Literature in the Light of the Emblem. Toronto: University of Toronto Press.

Dixon, Victor. 1993. «Los emblemas morales de Sebastián de Covarrubias y las comedias de Lope». En Estado actual de los estudios sobre el Siglo de Oro, ed. Manuel García Martín, vol. I, 299-305. Salamanca: Ediciones Universidad.

Ferrer Valls, Teresa. 1995. «Teatros y representación cortesana. La Arcadia de Lope de Vega: una hipótesis de puesta en escena». Cuadernos de Teatro Clásico 8: 213-232.

Mariscal, George. 1981. «Iconografía y técnica emblemática en Calderón, La devoción de la Cruz». Revista Canadiense de Estudios Hispánicos 5 (3): 339-354.

Moir, Duncan W. 1971. «Lope de Vega's Fuente Ovejuna and the Emblemas morales of Sebastián de Covarrubias Horozco». En Homenaje a William L. Fichter, coord. A. David Kossoff y José Amor y Vázquez, 537-546. Madrid: Castalia.

Morley, S. Griswold y Courtney Bruerton. 1968. Cronología de las comedias de Lope de Vega. Madrid: Gredos.

Oleza, Joan. 1986. «La propuesta teatral del primer Lope de Vega». En Teoría y prácticas escénicas. II: La comedia, ed. José Luis Canet, 251-308. Londres: Tamesis Books.

Oteiza, Blanca. 2001. «Aspectos emblemáticos y pictóricos en el teatro de Tirso de Molina». En Tirso de Molina: textos e intertextos. Actas del Congreso Internacional organizado por el GRISO y la Universidad de Parma, (Parma, 7-8 de mayo de 2001), coord. Laura Dolfi y Eva Galar, 57-87. Pamplona: Instituto de Estudios Tirsianos.

Restrepo, Pablo. 1995. La estructura y la función del emblema en el teatro de Tirso de Molina. Ann Arbor: University of Michigan.

Revueltas, Eugenia. 2003. «Estrategias emblemáticas en el teatro». En Estudios del teatro áureo: texto, espacio y representación. Actas selectas del X Congreso de la Asociación Internacional de Teatro Español y Novohispano de los Siglos de Oro, coord. Aurelio González, María Teresa Miaja de la Peña, Lillian von der Walde Moheno, Serafín González García y Alma Mejía, 139-155. [México]: Universidad Autónoma Metropolitana.

Rodríguez de la Flor, Fernando. 1995. Emblemas. Lecturas de la imagen simbólica. Madrid: Alianza.

Sáez Raposo, Francisco. 2016. «Proxemia y espacio dramático en el teatro pastoril del primer Lope de Vega». Anuario Lope de Vega 22: 409-431. https://doi.org/10.5565/rev/anuariolopedevega.152 
Sáez Raposo, Francisco. 2017a. «A vueltas con el espacio dramático en la comedia pastoril lopesca: La Arcadia». En Quel espace pour quel théâtre? Approche croisée des dramaturgies française et hispanique (XVI $-X X^{e}$ siècles), dir. Isabel Ibáñez y Hélène LaplaceClaverie, 87-108. Berna: Peter Lang.

Sáez Raposo, Francisco. 2017b. «Lope y Shakespeare frente a la "angustia de la tercera Dimensión": del drama pastoril a la tragedia histórica». Anagnórisis. Revista de Investigación Teatral 15: 270-293.

Sebastián, Santiago. 1985. Alciato. Emblemas. Madrid: Akal.

Smith, Dawn L. 1985. «Tirso's Use of Emblems as a Technique of Representation in La mujer que manda en casa». Bulletin of the Comediantes 37 (1): 71-81.

Waltaus, Rina. 2001. «'Femme forte’ y emblema dramático: la Jezabel de Tirso y la Semíramis de Calderón». En Actas del V Congreso Internacional de la Asociación Internacional Siglo de Oro (Münster, 20-24 de julio de 1999), coord. Christoph Strosetzki, 1361-1370. Madrid: Iberoamericana.

White, Martin. 1998. Renaissance Drama in Action. An Introduction to Aspects of Theatre Practice and Performance. London - New York: Routledge.

Zafra, Rafael, ed. 2003. Los emblemas de Alciato traducidos en rimas españolas. Barcelona: Olañeta.

Zuzankiewicz, Marta Pilat. 2013. «La historia del zarévich Demetrio: una lectura emblemática de la comedia El príncipe perseguido». En Teatro y poder en el Siglo de Oro, ed. Mariela Insúa y Felix K. E. Schmelzer, 167-181. Pamplona: Servicio de publicaciones de la Universidad de Navarra.

Fecha de recepción: 15 de noviembre de 2018.

Fecha de aceptación: 28 de enero de 2019. 
